\title{
Expression analysis and subcellular localization of the Arabidopsis thaliana G-protein $\beta$-subunit AGB1
}

\author{
David J. Anderson · José R. Botella
}

Received: 4 January 2007/Revised: 21 March 2007 / Accepted: 23 March 2007 / Published online: 10 May 2007

(C) Springer-Verlag 2007

\begin{abstract}
Heterotrimeric GTP-binding proteins (G-proteins), consisting of $\mathrm{G} \alpha, \mathrm{G} \beta$, and $\mathrm{G} \gamma$ subunits, function as molecular switches in many eukaryotic signal transduction pathways. In contrast to many eukaryotes, plants contain very few G-protein subunit isoforms that mediate a diverse array of signalling functions. We investigated the contribution of cell type-specific expression and subcellular localization to this multifunctional signalling capacity for the Arabidopsis thaliana $\mathrm{G} \beta$ subunit, AGB1. Analysis of $A G B 1$ promoter:: $\beta$-glucuronidase (GUS) fusions in germinating seeds, seedlings, and flowering plants revealed that $A G B 1$ is widely expressed throughout development in a complex manner. As well as demonstrating similarities to existing Arabidopsis G-protein subunit expression data, several features of the $A G B 1$ expression pattern align closely with known or proposed G-protein functions. A C-terminal AGB1-green fluorescent protein (GFP) fusion was localized at the plasma membrane and in the nucleus of leaf epidermal cells, trichomes and root cells, supporting previous evidence that plant G-protein functionality relies on subcellular compartmentalization.
\end{abstract}

Communicated by P. Lakshmanan.

D. J. Anderson · J. R. Botella ( $₫)$

Plant Genetic Engineering Laboratory,

School of Integrative Biology,

The University of Queensland,

St. Lucia, QLD 4072, Australia

e-mail: j.botella@uq.edu.au

Present Address:

D. J. Anderson

The Australian Institute for Bioengineering

and Nanotechnology, The University of Queensland,

St. Lucia, QLD 4072, Australia
Keywords Heterotrimeric G-protein - Arabidopsis thaliana - Signal transduction - Guard cell · Trichome . Root cap

$\begin{array}{ll}\text { Abbreviations } \\ \text { CLSM } & \text { Confocal laser scanning microscopy } \\ \text { ER } & \text { Endoplasmic reticulum } \\ \text { GFP } & \text { Green fluorescent protein } \\ \text { G-protein } & \text { Heterotrimeric GTP-binding protein } \\ \text { GPCR } & \text { G-protein-coupled receptor } \\ \text { GUS } & \beta \text {-glucuronidase } \\ \text { rRNA } & \text { ribosomal RNA }\end{array}$

\section{Introduction}

Heterotrimeric GTP-binding protein (G-protein)-coupled pathways are among the most conserved signal transduction systems in eukaryotes (Offermanns 2003). G-proteins consist of $\mathrm{G} \alpha(40-46 \mathrm{kDa}), \mathrm{G} \beta(37-44 \mathrm{kDa})$, and $\mathrm{G} \gamma$ (6-9 kDa) subunits, with $\mathrm{G} \alpha$ and $\mathrm{G} \gamma$ subunits carrying lipid modifications that enable membrane attachment (Casey 1995). G-proteins act as molecular switches, wherein inactive heterotrimers recognise G-protein-coupled receptors (GPCRs) at the plasma membrane. The agonist-stimulated GPCR causes the $\mathrm{G} \alpha$ subunit to exchange bound GDP for GTP, resulting in dissociation of the G $\beta \gamma$ dimer. Free $\mathrm{G} \alpha$ or $\mathrm{G} \beta \gamma$, or both, are active signal transducers to downstream effectors. Hydrolysis of GTP to GDP by the intrinsic GTPase activity of $\mathrm{G} \alpha$ allows the heterotrimer to reform, completing the signalling cycle. In mammals, heterotrimer combinations of $20 \mathrm{G} \alpha, 5 \mathrm{G} \beta$, and $12 \mathrm{G} \gamma$ subunits (Malbon 2005) provide signalling specificity for most of the vast family of GCPRs encoded by over 800 
genes (Pierce et al. 2002). G-protein-coupled signalling pathways are involved in numerous mammalian physiological processes and are implicated in many disease states, making them the single most important target for therapeutic drugs (Pierce et al. 2002). In addition to cell signalling, G-proteins fulfil key roles in developmental signalling (Malbon 2005), including conserved functions in mitosis (Hampoelz and Knoblich 2004).

In contrast to mammals and other eukaryotes, plants possess only a few conventional G-protein subunits, with the Arabidopsis genome containing one $\mathrm{G} \alpha$, one $\mathrm{G} \beta$, and two $\mathrm{G} \gamma$ subunits (Assmann 2005). Recent studies using knockout mutants for Arabidopsis G-protein subunits have demonstrated signalling functions associated with a number of plant developmental and physiological processes (Perfus-Barbeoch et al. 2004). How plant G-proteins carry out multiple signalling roles with one or two isoforms of each subunit is unclear. It is apparent that some signalling functions are cell-type dependent, which could result from interaction with different receptors/effectors expressed in different cell types, or from the balance of $\mathrm{G} \alpha$ and $\mathrm{G} \beta \gamma$ subunits in the cell type, perhaps working antagonistically (Jones and Assmann 2004). The subcellular location of Gproteins and cognate receptors/effectors may be an additional determinant of signalling specificity. In addition to the plasma membrane, mammalian and other eukaryotic Gproteins are associated with the cytoskeleton, nucleus and endomembranes (Willard and Crouch 2000; Gotta and Ahringer 2001; Simonds et al. 2004). Hence, detailed information on the expression and subcellular localization of G-protein subunits and coupled components may be essential for understanding the operation of plant G-proteins in multiple signalling pathways.

In Arabidopsis, expression of the $\mathrm{G} \alpha$ subunit gene GPAl (Ma et al. 1990) has been extensively characterized by immunohistological (Weiss et al. 1993) and promoter:: $\beta$ glucuronidase (GUS) fusion approaches (Huang et al. 1994). These revealed a complex expression pattern spanning most organs and stages of development, with consistent expression in meristematic and vascular tissues suggesting roles in cell division and elongation, nutrient accumulation and transport. Comparatively less is known about the Arabidopsis G $\beta$ gene AGB1 (Weiss et al. 1994) and $\mathrm{G} \gamma$ genes $A G G 1$ (Mason and Botella 2000) and $A G G 2$ (Mason and Botella 2001). Recently, Chen et al. (2006b) reported a promoter::GUS analysis of all three genes as part of a study of the Arabidopsis AtMLO gene family that encodes potential plant-specific GPCRs. Analysis of seedling and floral organs showed ubiquitous expression of all three genes, prominent in meristematic and vascular tissues, and containing overlap consistent with the hypothesis that G-proteins form heterotrimers.
In Arabidopsis meristematic cells, GPA1 is present in the endoplasmic reticulum (ER), Golgi and plasma membranes, but not in nuclei or chloroplasts (Weiss et al. 1997). Similarly, $\mathrm{G} \alpha$ and $\mathrm{G} \beta$ were localized to the plasma membrane and ER in embryo and endosperm tissue of Nicotiana plumbaginifolia (Kaydamov et al. 2000). Tobacco G $\beta$ is located in the plasma membrane and the nucleus of leaf cells, but not in chloroplasts, tonoplasts, mitochondria, the ER or the Golgi apparatus (Peškan and Oelmüller 2000). In Arabidopsis, it has been established that AGB1 is a peripheral, membrane-bound protein, probably by association with a $\mathrm{G} \gamma$ subunit (Obrdlik et al. 2000). Recently, green fluorescent protein (GFP) fusions of both GPA1 and AGB1 were localized to the plasma membrane in root cells, and preferentially at the cell plate in newly divided cells, suggesting a role in cytokinesis (Chen et al. 2006a). No subcellular localization of AGG1 or AGG2 has been reported.

To provide insights into plant G-protein signalling functions, we investigated the expression pattern and subcellular localization of AGB1. We present a comprehensive study of $A G B 1$ promoter::GUS expression. Although similar in some respects to the report by Chen et al. (2006b), our results reveal additional aspects of $A G B 1$ expression that complement existing functional data and suggest new location-specific roles. We also show that an AGB1-GFP fusion is located in the nucleus as well as at the plasma membrane, adding to previous evidence that plant G-proteins function at multiple subcellular locations.

\section{Materials and methods}

\section{Northern blot analysis}

Arabidopsis thaliana ecotype Columbia tissues were harvested from plants grown in a mixture of $60 \%$ UC potting mix type C (Matkin and Chandler 1979) and 40\% vermiculite $(\mathrm{v} / \mathrm{v})$. After sowing in pots, seeds were vernalized by incubation at $4^{\circ} \mathrm{C}$ for 3-5 days, then transferred to a growth room at $21 \pm 3^{\circ} \mathrm{C}$ under a 16 -h photoperiod with a light intensity of $50 \mu \mathrm{E} \mathrm{m}^{-2} \mathrm{~s}^{-1}$ provided by white fluorescent tubes. Apart from whole 14-day-old seedlings, all other samples were taken from flowering plants approximately 6 weeks old. Developing and mature rosette and cauline leaves (excluding petioles) were sampled at the same time and distinguished by leaf blade length: developing rosette leaves, $1 \mathrm{~cm}$; mature rosette leaves, $3 \mathrm{~cm}$; developing cauline leaves, $0.5 \mathrm{~cm}$; mature cauline leaves, $1 \mathrm{~cm}$. Extraction of total RNA, northern blotting, and hybridisation were performed as described by Etheridge et al. (1999) using ${ }^{32}$ P-labelled probes, and hybridised blots were 
visualized using a PhosphorImager $\mathrm{SI}^{\mathrm{TM}}$ and quantified with ImageQuaNT ${ }^{\mathrm{TM}}$ software (Molecular Dynamics, Inc.). A SalI/NotI fragment of an AGBI EST clone (ID \#162P20T7, obtained from the Arabidopsis Biological Resource Centre, http://www.biosci.ohio-state.edu/ plantbio/Facilities/abrc/) was used for the hybridization probe. The blot was re-probed with a wheat ribosomal RNA gene (Gerlach and Bedbrook 1979) for total RNA loading normalization.

\section{AGB1p::GUS and AGB1-GFP constructs}

For the $A G B 1 p::$ GUS construct, the $A G B 1$ promoter region was amplified by PCR from Arabidopsis genomic DNA using the AGB5 primer (5'-AA CTC GAG TTA CAA GCG AGC TTG-3'), located approximately $2.3 \mathrm{~kb}$ upstream from the transcription initiation site, and the AGB4 primer (5'-TTG GAT CCA $\underline{\text { TTC CGG GAT CAG ACT TAG GCT }}$ TC- $3^{\prime}$ ), located at the $3^{\prime}$ end of the $A G B 15^{\prime}$ UTR (annealing regions are underlined, the $A G B 1$ start codon shown in bold, and XhoI and BamHI sites, respectively, are indicated by italics). The primers AGB5 correspond to bases 17,79617,779, and AGB4 to bases 15,273-15,297 of the Arabidopsis chromosome 4 BAC clone T4L20 (Genbank entry AL023094). The resulting PCR product was cloned into pGEM-T Easy ${ }^{\circledR}$ vector (Promega Corp.) and confirmed by sequencing. The $A G B 1$ promoter/5'UTR fragment was excised with $X h o \mathrm{I} /$ Bam HI, and ligated into pAOV-intronGUS (containing the intron-gusA reporter gene (Ohta et al. 1990) inserted into the CaMV35S promoter/nos terminator cassette of pAOV (Mylne and Botella 1998); kindly provided by Dr. J. S. Mylne) from which the CaMV35S promoter had been removed by digestion with XhoI/BamHI. The resulting $A G B 1$ promoter-intronGUS fusion binary construct was named $A G B 1 p:$ GUS.

For the AGB1-GFP construct, an $A G B 1$ cDNA was amplified by reverse transcription-PCR (RT-PCR) from RQ1 DNaseI (Promega Corp.) treated total RNA extracted from Arabidopsis flowers using the primers AGB2 (5' ATC TCG AGA ATC ACT CTC CTG TGT CCT CC $3^{\prime}$, annealing region underlined, $X h o \mathrm{I}$ site italicised) and AGB3 (5' CGT GTT TGT GTC TTG ACT GAT TC $3^{\prime}$ annealing region underlined). These primers correspond to 1,338-1,318 and $13-35$ of the AGB1 cDNA sequence (Genbank entry U12232), respectively. The pBluescript SKII- ${ }^{\circledR}$ vector (Stratagene Corp.) was modified by removing the XhoI site by digestion, filling of the ends and re-ligation. This plasmid was then digested with SmaI and used to blunt-clone the $1.32 \mathrm{~kb} A G B 1$ RT-PCR product. To create the AGB1-GFP fusion, a clone containing the $A G B 1$ cDNA in T7 $\rightarrow \mathrm{T} 3$ orientation was digested with $X h o I$, and then ligated to an XhoI fragment containing the mGFP5 gene excised from pBS-GFP. The plasmid pBS-GFP (kindly provided by Dr. T. V. Humphrey) comprises mgfp5-ER (Siemering et al. 1996) amplified without the ER signal peptide or ER retention signal using the primers GFP 1 (5'-GC CTC GAG AGT AAA GGA GAA GAA CTT-3') and GFP 2 (5'-CG GAG CTC TCA TTT GTA TAG TTC ATC-3') and ligated into EcoRV-cut pBluescript SKII- ${ }^{\circledR}$. The binary transformation vector AGB1GFP was created by excising the AGB1-mGFP5 fusion with BamHI/PstI and sub-cloning into pSOV2 (Mylne and Botella 1998).

\section{Production of transgenic Arabidopsis}

Binary vectors were introduced into Agrobacterium tumefaciens strain LBA4404 (Hoekema et al. 1983) by triparental mating as described by Svab et al. (1995) using the E. coli helper strain pRK2013 (Ditta et al. 1980). Wild type Arabidopsis thaliana ecotype Columbia was transformed according to the vacuum infiltration method of Bechtold et al. (1993) and $\mathrm{T}_{1}$ transformants selected by spraying with $0.4 \% \mathrm{v} / \mathrm{v} \mathrm{Basta}{ }^{\circledR}$ (Hoechst AG), initially at the emergence of cotyledons, then twice again at 3-day intervals. The $35 \mathrm{~S}$ promoter control line (transformed with the pAOV-intronGUS vector previously described) was kindly provided by Dr. J. S. Mylne.

\section{GUS histochemical analysis}

For comparative purposes, GUS histochemical characterization of the AGB1p::GUS lines was modelled on a study of the Arabidopsis $\mathrm{G} \alpha$ subunit GPAl promoter (Huang et al. 1994). Four developmental stages were examined: germinating seeds (36 h after imbibition), 5-day-old seedlings (cotyledons open), 11-day-old seedlings (first leaves expanded, second leaves developing), and flowering mature plants. Samples were immersed in a staining solution (2 mM X-gluc, $0.5 \%$ Triton X-100, $0.1 \%$ Tween 20, $0.5 \mathrm{mM} \mathrm{K}_{3} \mathrm{Fe}(\mathrm{CN})_{6}, \quad 0.5 \mathrm{mM} \mathrm{K}_{4} \mathrm{Fe}(\mathrm{CN})_{6} \cdot 3 \mathrm{H}_{2} \mathrm{O}, \quad 10 \mathrm{mM}$ $\mathrm{Na}_{2}$ EDTA and $50 \mathrm{mM}$ sodium phosphate buffer, $\mathrm{pH}$ 7.0), vacuum infiltrated three times for $5 \mathrm{~min}$, then incubated at $37^{\circ} \mathrm{C}$ for $24 \mathrm{~h}$. Stem cross-sections were hand sectioned prior to staining. After staining, samples were cleared by several changes of $70 \%$ ethanol. Photographs were taken using a Camedia C-3040 Zoom digital camera attached to BH2 compound or SZ11 stereo microscopes (Olympus Corp.). No GUS staining was observed in any of the wild type negative controls that were performed for each sample.

Confocal laser scanning microscopy (CLSM)

Transgenic $\mathrm{T}_{2}$ Arabidopsis seeds were surface sterilised by incubation in a 1:1 mixture of ethanol: hydrogen peroxide 
(3\%) for 5 minutes, washed three times in sterile distilled water, and resuspended in sterile $0.15 \%$ agar. Seeds were plated on germination medium containing $1 \times$ MS Salts, $1 \times$ MS vitamins, $1 \%$ sucrose, $1 \%$ agar, $\mathrm{pH} 5.7$ (Murashige and Skoog 1962) and grown in conditions as described previously. After approximately 11 days, seedlings were examined by mounting in water under glass cover slips. GFP fluorescence was observed using a Bio-Rad MRC-600 confocal laser scanning microscope equipped with a 3-line krypton-argon laser, a Bio-Rad K1/K2 filter set and a Zeiss $63 \times$ Planapo 1.4 numerical aperture oil-immersion objective. Composition of dual channel images and image processing were carried out using Confocal Assistant version 4.02 (BioRad Corp.) and Image J 1.33u (Rasband 2005) software.

\section{Results}

Northern blot analysis of $A G B 1$ mRNA expression

Previous northern blot analysis of $A G B 1$ expression showed the presence of transcripts in whole roots, leaves and flowers (Weiss et al. 1994). To provide a reference point for detailed expression analysis, we performed an expanded northern blot analysis of whole seedlings and nine different mature plant tissue types (Fig. 1). AGB1 transcripts were present in 14-day-old seedlings and all mature plant tissues at varying levels. Developing and mature rosette leaves, roots and stems contained the highest transcript levels, while siliques showed the lowest level.

$A G B 1 p:: G U S$ expression in germinating seeds and young seedlings

To investigate the $A G B 1$ expression pattern in more detail, we generated transgenic Arabidopsis plants expressing an $A G B 1$ promoter::GUS transcriptional fusion, $A G B 1 p:$ : GUS. The arbitrarily selected $2.5 \mathrm{~kb} A G B 1$ promoter region also contains the entire 459 bp coding region of the ASK12 gene, starting $755 \mathrm{bp}$ upstream of the AGB1 translation initiation site. ASK12 is a member of the Arabidopsis SKP1-like gene family that is thought to be involved in ubiquitin-mediated proteolysis (Zhao et al. 2003). Histochemical GUS staining of 11-day-old $\mathrm{T}_{2}$ seedlings revealed an identical expression pattern at varying intensity levels in 12 independent $A G B 1 p:$ :GUS lines, which was typified by strong expression in the stem and petioles (results not shown). Three lines with single copy T-DNA insertions were selected for further characterization and confirmed by Southern blot hybridization as independent transformants (data not shown).
In germinating seeds at $36 \mathrm{~h}$ after imbibition, the strongest GUS expression was observed in the hypocotyl and apical meristem region (Fig. 2b-d). During early development, GUS expression progressively appeared in cotyledons and root tips (Fig. 2b-d). A similar overall pattern was observed for 5-day-old seedlings (Fig. $2 \mathrm{f}-\mathrm{h}$ ). Staining was most intense in the petioles and stems, including the apical meristem region (Fig. $2 \mathrm{i}-\mathrm{j}$ ), but was faint or undetectable in the cotyledons and leaf primordia. $A G B 1 p:$ :GUS expression was observed in the root stele (Fig. 2k), although not in the lower root region close to the root tip, including the zones of cell division, elongation and differentiation (Fig. 21). No staining was observed in the root hairs (Fig. 2j, k). Close inspection of GUS expression in the root tip showed that it was confined to the root cap (Fig. 2m). For both germinating seeds and 5-day-old seedlings, $A G B 1$ expression was considerably weaker compared to the $35 \mathrm{~S}$ promoter::GUS controls (Fig. 2a, e).

In 11-day-old seedlings $A G B 1 p:: G U S$ expression was strongest in petioles and hypocotyls, including the apical meristem region (Fig. 3b-d). Staining in the petioles continued along the mid veins of leaf primordia and leaves, fading towards the leaf tip (Fig. 3i, j). Although the leaf

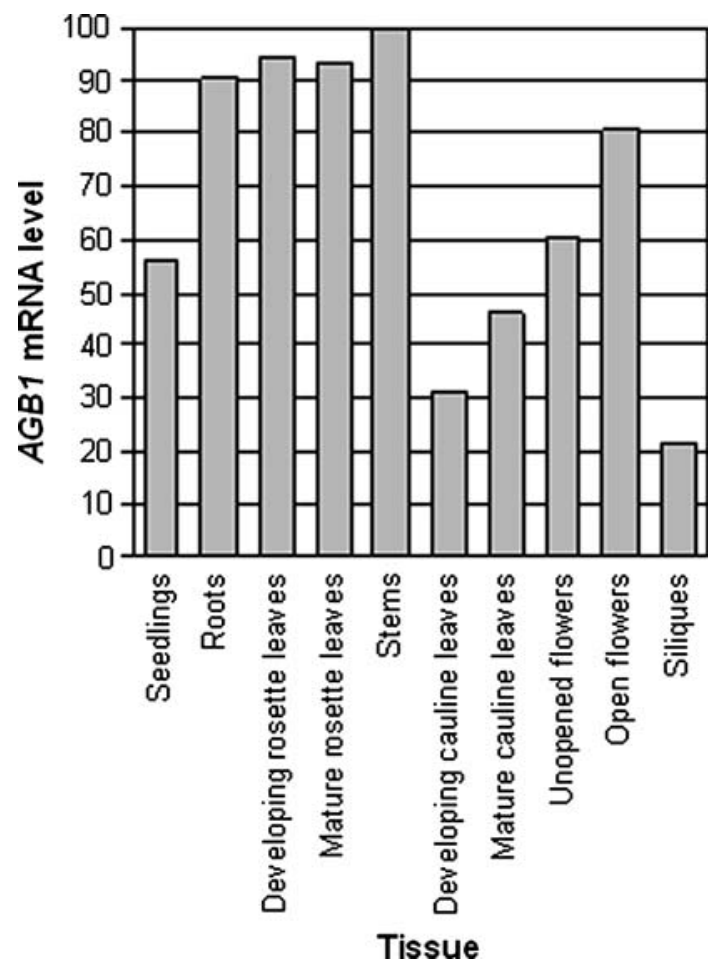

Fig. 1 AGB1 mRNA levels in Arabidopsis seedlings and mature plant tissues. Northern blot analysis was performed using $10 \mu \mathrm{g}$ total RNA for each tissue type. Hybridization of an $A G B 1$ probe was quantified and normalized against an rRNA loading control probe. An arbitrary value of 100 was given to the maximum value and the rest expressed as a percentage of the maximum 
blades appeared to be unstained, detailed examination revealed low-level GUS expression in the guard cells (Fig. 3n, o). Comparatively stronger GUS expression was seen in guard cells, mesophyll cells and vascular tissues of cotyledons (Fig. 3q, r). Cell-specific GUS expression was also found in trichomes of leaf primordia and mature leaves (Fig. 3i, p). GUS staining was present throughout most of the root system, including root hairs (Fig. 3f-h), with the strongest staining observed in the stele (Fig. 3k-m). Examination of root tips showed that the GUS expression in the stele originates around the zone of differentiation (Fig. 31). Strong GUS expression was present in the root cap as observed for 5-day-old seedlings, but was also found in the adjacent root meristem and zone of cell division, fading in the zone of elongation (Fig. 31, m). This pattern was also seen in lateral roots (Fig. 3m). As observed for germinating seeds and 5-day-old seedlings, $A G B 1$ expression in 11-day-old Arabidopsis seedlings was considerably weaker than GUS lines driven by the $35 \mathrm{~S}$ promoter (Fig. 3a, e).

\section{$A G B 1 p::$ GUS expression in mature flowering plants}

Mature AGB1p::GUS plants showed GUS expression in floral tissues, with the highest levels observed in sepals and stamen filaments, lower levels found in the gynoecium and anthers, and very faint expression in petals (Fig. 4b, d). GUS expression was also observed in the floral buds of secondary branches, being more intense in bud primordia (Fig. 4e). In siliques, GUS expression was present in the wall and stalk, but absent from seeds (Fig. 4g). Similar to our observations in earlier developmental stages, mature AGB1p::GUS plants showed intense GUS staining in stems and rosette petioles, extending into the mid veins and vascular tissue of the blades (Fig. 4k, o). GUS expression in cauline leaves followed the same pattern, but was comparatively weaker (Fig. 4i). Cell-specific GUS expression was present in trichomes of rosette leaves (Fig. 41, m) and cauline leaves (data not shown). GUS staining was present in all stem tissue types, with greater intensity observed in the cortex and vascular tissues (Fig. 4o, q). As for 11-day-old seedlings, GUS expression was present in most of the root system and was strongest in the stele. However, staining was almost absent in lateral roots and less obvious in root caps (Fig. 4s, t). Strong GUS expression was observed in the $35 \mathrm{~S}$ promoter control line for all tissues examined (Fig. 4a, c, f, h, j, n, p, r).

\section{Subcellular localization of AGB1 by GFP tagging}

We investigated the subcellular localization of AGB1 using GFP tagging. To minimise the possibility of interference
Fig. 2 Histochemical analysis of GUS expression in AGB1p::GUS germinating and 5-day-old Arabidopsis seedlings. Seedlings $36 \mathrm{~h}$ after imbibition: a 35S::GUS; b-d $A G B 1 p::$ GUS lines 26.3.3, 14.1.3 and 30.4.3, respectively. Five-day-old seedlings: e 35S::GUS; f-h AGB1p::GUS lines 14.1.3, 26.3.3 and 30.4.3, respectively. Representative AGB1p::GUS expression in 5-day-old seedlings: $\mathbf{i}$ apical region; $\mathbf{j}$ shoot-root junction; k upper root; I lower root; m root tip. Arrows indicate staining in root tip. Bars a-d $250 \mu \mathrm{m}$; e-h $1 \mathrm{~mm}$; i-j $250 \mu \mathrm{m} ; \mathbf{k}-\mathbf{m} 100 \mu \mathrm{m}$
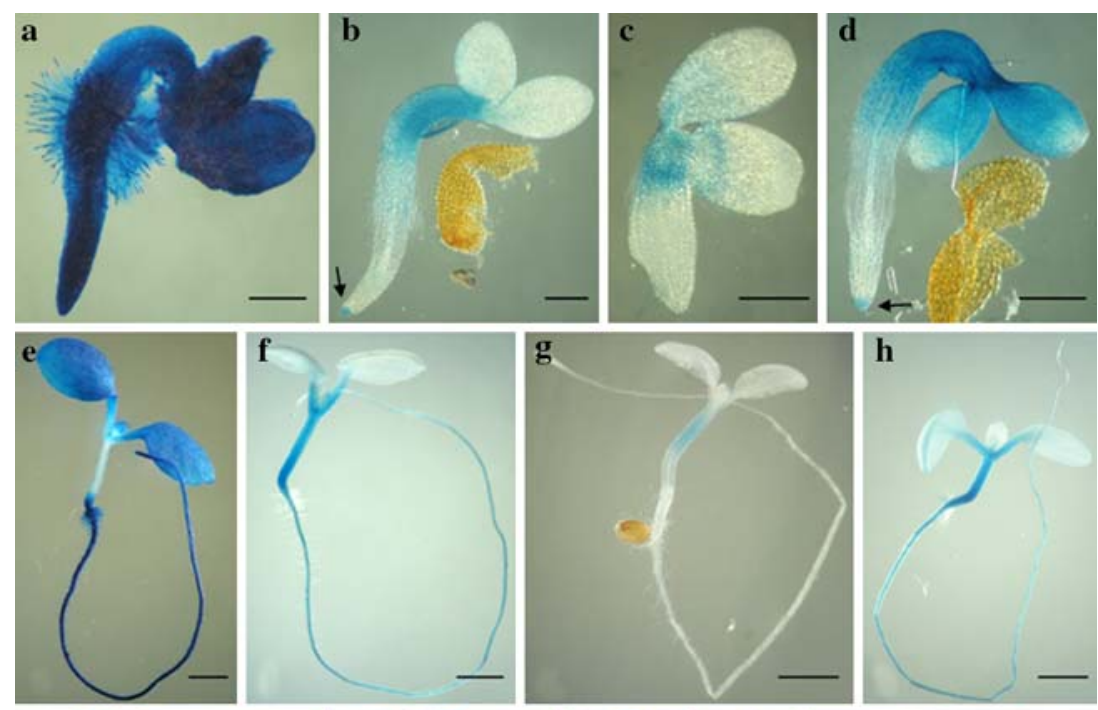

h
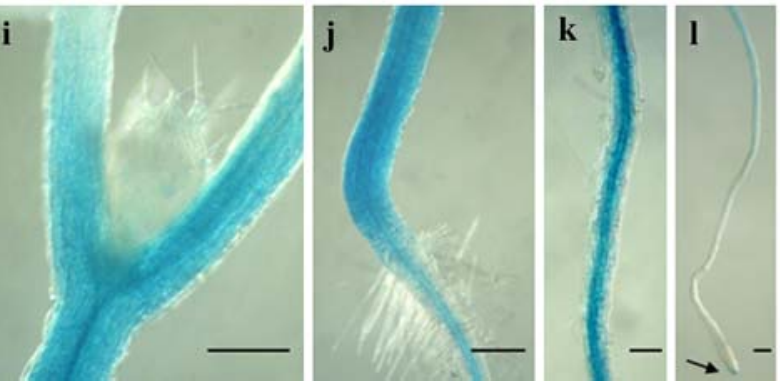

m 
Fig. 3 Histochemical analysis of GUS expression in 11-dayold AGB1p::GUS Arabidopsis seedlings. GUS expression in shoots: a 35S::GUS;

b-d AGB1p::GUS lines 14.1.3, 26.3.3 and 30.4.3, respectively. GUS expression in roots: e 35S::GUS; f-h AGB1p::GUS lines 14.1.3, 26.3.3 and 30.4.3, respectively. Representative detailed GUS expression in AGB1p::iGUS lines: $\mathbf{i}, \mathbf{j}$ apical region; $\mathbf{k}$, l primary root tip; m lateral roots; $\mathbf{n}$ abaxial view of a leaf and detail in $\mathbf{o}$ showing staining in guard cells; $\mathbf{p}$ leaf trichome; $\mathbf{q}$ abaxial view of a cotyledon, with detail in $\mathbf{r}$. Arrows indicates staining in trichomes. Bars $\mathbf{a}-\mathbf{h} 1 \mathrm{~mm}$; i-l $250 \mu \mathrm{m} ; \mathbf{n}, \mathbf{p}, \mathbf{q} 100 \mu \mathrm{m}$; $\mathbf{m}, \mathbf{o}, \mathbf{r} 25 \mu \mathrm{m}$
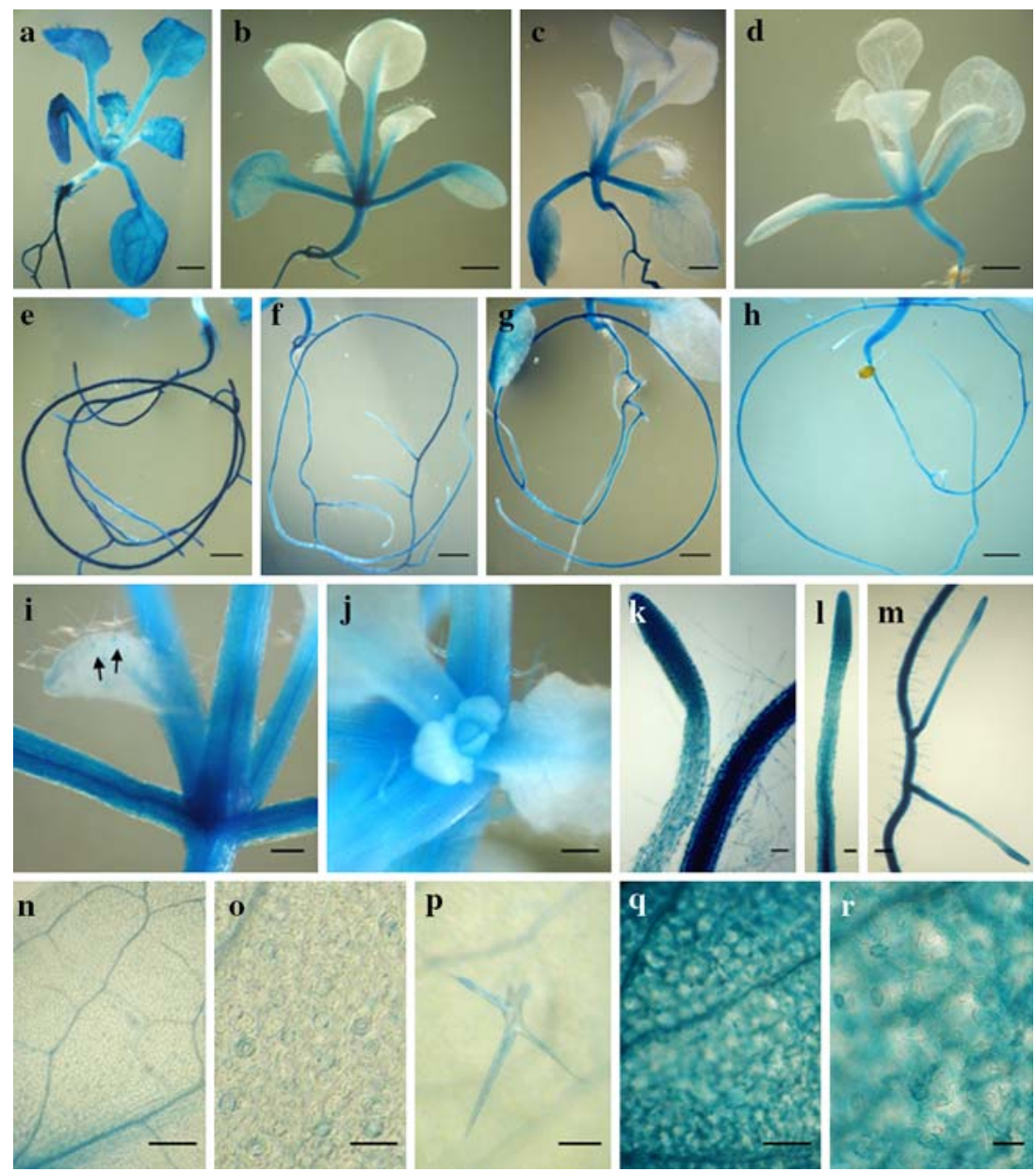

with $\mathrm{G} \beta \gamma$ dimer formation and membrane anchorage, a Cterminal AGB1-GFP fusion was chosen. This arrangement is not expected to interfere with membrane association, and indeed a similar GFP fusion expressed in transgenic tobacco was shown to associate with microsomes in the same way as AGB1 in wild type Arabidopsis (Obrdlik et al. 2000). The AGB1-GFP fusion was created by adding the coding region of $m G F P 5$ (Haseloff and Siemering 1998) immediately behind the full coding region of $A G B 1$. Transgenic Arabidopsis plants expressing the AGB1-GFP fusion protein under the control of the $35 \mathrm{~S}$ promoter were examined by confocal laser scanning microscopy (CLSM). Eleven-day-old $\mathrm{T}_{2}$ seedlings from five independently transformed lines showed identical subcellular localization patterns, characterized by GFP fluorescence at the periphery of the cytoplasm in leaf epidermal cells, suggesting that AGB1-GFP was present at the plasma membrane (Fig. 5ac). The fluorescent layer was not homogenous, but instead formed discrete node-like structures (Fig. 5g). Although weaker than the non-targeted and ER-targeted GFP controls (Fig. 5d, e), the GFP fluorescence in AGB1-GFP transgenic lines was clearly distinguishable from autofluorescence in wild type leaf epidermal cells (Fig. 5f). No
Agrobacterium growth was observed when the AGB1-GFP lines were grown on nutrient media, and the Agrobacterium strain containing the AGB1-GFP construct used for Arabidopsis transformation did not show significant fluorescence when examined by CLSM with identical settings (data not shown). Hence, the fluorescence pattern observed of the AGB1-GFP fusion could not have resulted from persistent Agrobacterium growth.

In the absence of a targeting signal, mGFP5 localises to the cytoplasm and also diffuses into the nucleus (Haseloff et al. 1997). The AGB1-GFP fluorescent pattern is clearly distinguishable from the pattern observed in non-targeted mGFP5 plants, being thinner and different in shape (Fig. 5c, d). The AGB1-GFP fusion fluorescent signal is also distinct from endoplasmic reticulum (ER)-targeted mGFP5 (Haseloff et al. 1997; Haseloff 1999), which lines the periphery of the cytoplasm but also forms a reticulate pattern within it and surrounds the nucleus (Fig. 5e; Haseloff et al. 1997). In some cells, the AGB1-GFP fluorescent signal also forms filamentous structures (Fig. 5c, h) that may represent the cytoskeleton or cell cortex. However, ER-targeted mGFP5 has a similar appearance (Fig. 5e), suggesting that the filamentous structures simply 
Fig. 4 Histochemical analysis of GUS expression in mature AGB1p::GUS Arabidopsis

plants (representative images). a, b 35S::GUS and $A G B 1 p:$ :GUS inflorescences, respectively; c, d 35S::GUS and $A G B 1 p:$ GUS flowers,

respectively; e developing AGB1p::GUS inflorescence; f, g 35S::GUS and AGB1p::GUS siliques, respectively; h, i 35S::GUS and AGB1p::GUS cauline leaves, respectively; j, k 35S::GUS and AGB1p::GUS rosette leaves, respectively; $\mathbf{l}$ adaxial view of $A G B 1 p::$ GUS rosette leaf showing staining of trichomes and vascular tissue; $\mathbf{m}$ staining in trichomes of an AGB1p::GUS rosette leaf; n-o 35S::GUS and AGB1p::GUS stem pieces, respectively; p, q 35 S::GUS and AGB1p::GUS stem transverse sections, respectively $(E$ epidermis; $C$ cortex; $X$ xylem; $P$ phloem; $P i$ pith); r 35S::GUS roots; s-t AGB1p::GUS roots (arrows indicate staining in root tips). Bars a-b $1 \mathrm{~mm}$;

c-e $250 \mu \mathrm{m} ; \mathbf{f}-\mathbf{k} 1 \mathrm{~mm}$;

l-m $250 \mu \mathrm{m}$; n, o, $500 \mu \mathrm{m}$;

p, q $100 \mu \mathrm{m} ; \mathbf{r}-\mathbf{t} 250 \mu \mathrm{m}$
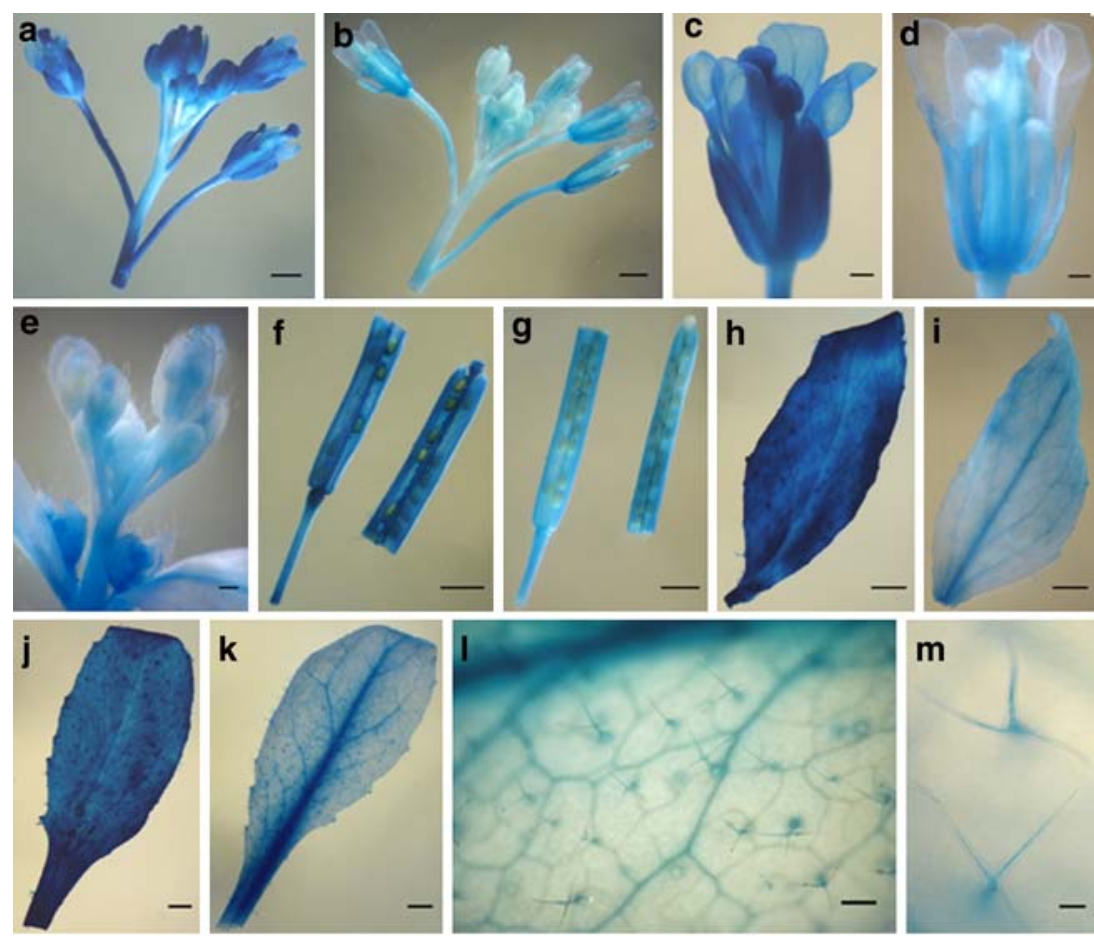

m
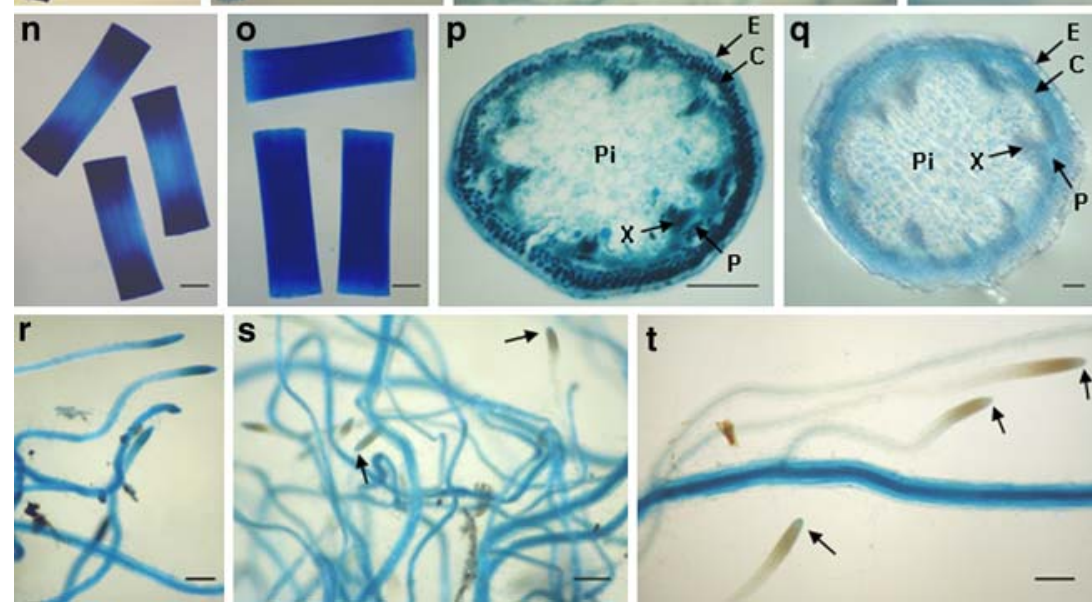

represent GFP fluorescence associated with the inner boundary of the cytoplasm that is closely aligned with the plane of the optical section.

In addition to the plasma membrane, the AGB1-GFP fusion protein is associated with fluorescently labelled structures (Fig. 5c, g) that can be identified as nuclei by their number, size, appearance, and position within the cells when compared with non-targeted and ER-targeted GFP lines (Fig. 5d, e). Non-targeted mGFP5 diffuses into nuclei because it is smaller $(26.8 \mathrm{kDa})$ than the nuclear pore exclusion limit of approximately 40-60 kDa (Kohler 1998). Thus the presence of the $67.9 \mathrm{kDa}$ AGB1-GFP fusion protein in the nucleus indicates active targeting. An identical pattern of plasma membrane and nuclear localization was also observed in leaf trichomes and roots (Fig. 5h, i). In the large trichome cells, non-fluorescent nucleoli were clearly identified, demonstrating that AGB1-GFP is located within the nucleus and not associated with the nuclear membrane. In both trichomes and root cells, the plasma membrane-localized fluorescent signal contained node-like structures similar to those seen in leaf epidermal cells.

\section{Discussion}

The AGB1p::GUS expression pattern shows similarities to previous expression data for Arabidopsis G-protein subunits as well as additional features

The AGB1p::GUS expression pattern reported in this work reveals a number of similarities, as well as some differences with previously reported expression data for 
Fig. 5 Subcellular localization of AGB1-GFP at the plasma membrane and in the nucleus by CLSM. a-c Leaf epidermal cells expressing AGB1-GFP: a green channel (GFP); b red channel (chlorophyll); c merged green and red channels. d-h Merged green and red channel images of leaf epidermal cells: $\mathbf{d}$ non-targeted GFP (image kindly provided by Dr. A. Gnanasambandam, The University of Queensland); e ER-targeted GFP; $\mathbf{f}$ wild-type, captured and processed using settings identical to $\mathbf{c} ; \mathbf{g}$ detail of AGB1-GFP in leaf epidermal cells; $\mathbf{h}$ base of a leaf trichome surrounded by epidermal cells; i green channel image of a root longitudinal optical section (colour omitted). $N$ nucleus; $\mathrm{Nu}$ nucleolus; $N S$ node structures. Bars all images $10 \mu \mathrm{m}$
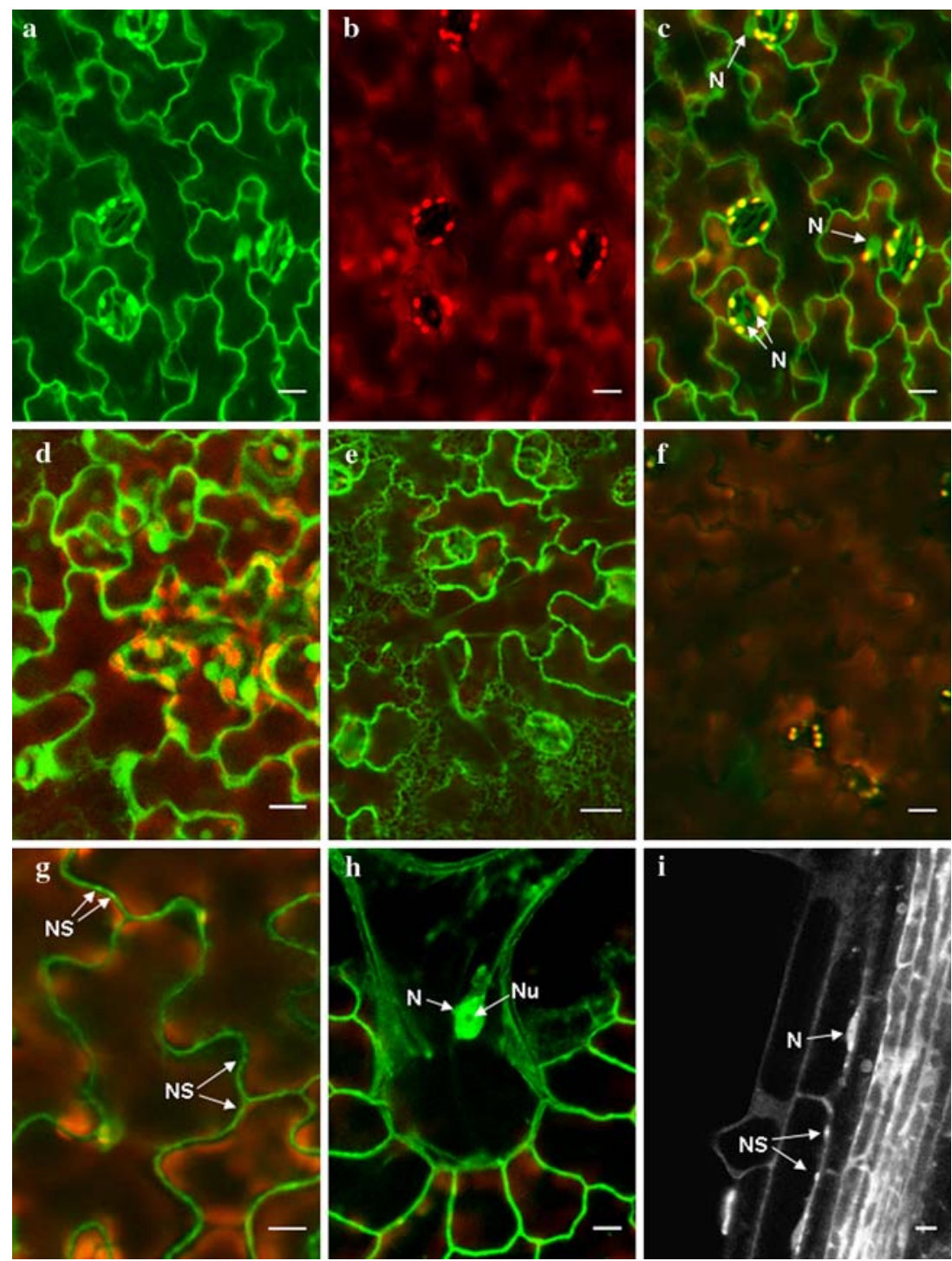

Arabidopsis $\mathrm{G} \alpha, \mathrm{G} \beta$ and $\mathrm{G} \gamma$ subunits (Table 1). Our results are similar to those reported by Chen et al. (2006b) in seedlings, hypocotyls, cotyledons, leaves and shoot/root junction. However, Chen et al. (2006b) reported ubiquitous staining of roots, whereas we observed specific expression in the root caps of lateral and primary roots, combined with an absent or reduced staining pattern in the root meristem and elongation zone. We also observed previously unreported $A G B 1$ promoter expression in guard cells, mesophyll tissue of cotyledons, trichomes and whole siliques (but not in seeds).

It is likely that some or all of these differences are due to our use of a larger genomic fragment $(2.5 \mathrm{~kb})$, compared with the $755 \mathrm{bp}$ promoter region used by Chen et al. (2006b) that was bound by the stop codon of the neighbouring ASK12 gene. It could be argued that some of the $A G B 1 p:$ GUS staining pattern resulted from read-through transcription or other effects of the ASK12 gene that was included in the $2.5 \mathrm{~kb}$ genomic region we used. However, the ASK12 gene has extremely low levels of expression in all tissues tested by RT-PCR except for flowers, where the expression is still low but detectable (Zhao et al. 2003; Takahashi et al. 2004). In addition, ASK12 promoter::GUS fusion studies showed expression that was exclusively restricted to near the top of the stigma (Takahashi et al. 2004). Therefore, the observed differences are probably due to the larger promoter fragment used in our study that should more closely reflect wild type $A G B 1$ gene expression.

In some aspects, the $A G B 1 p::$ GUS expression pattern is quite similar to reported expression data for $G P A 1, A G G 1$ and $A G G 2$ (Huang et al. 1994; Chen et al. 2006b). This is to be expected, as the three G-protein subunits are thought to form functional heterotrimers. For example, 11-day-old seedlings for both $A G B 1 \mathrm{p}:: G U S$ and GPA1 promoter::GUS constructs showed expression in most of the root system, the hypocotyl, cotyledons, petioles and the vascular tissue 
Table 1 The AGB1p::GUS expression pattern shows similarities with promoter::GUS results for Arabidopsis G-protein subunit genes previously reported

\begin{tabular}{|c|c|c|c|c|c|c|c|}
\hline Stage & Organ & Region/tissue & GPAl & $A G B 1$ this study & $A G B 1$ & $A G G 1$ & $A G G 2$ \\
\hline \multirow{5}{*}{$\begin{array}{l}\text { Germinating } \\
\text { seedlings }\end{array}$} & & & $32 \mathrm{~h}$, light grown & $36 \mathrm{~h}$, light grown & \multicolumn{2}{|c|}{ 2-day-old, etiolated } & \\
\hline & Root & & ++ & $\mathrm{tp}++$ & - & - & \\
\hline & Hypocotyl & & - & ++ & - & - & \\
\hline & Cotyledons & & - & + (early stages) & + & ++ & \\
\hline & Shoot meristem & & - & ++ & ++ & + & \\
\hline \multirow{10}{*}{$\begin{array}{l}\text { 5-day-old } \\
\text { seedlings }\end{array}$} & Root & Cap & ++ & ++ & & - & \\
\hline & & Cell division zone & ++ & - & & - & \\
\hline & & Elongation zone & ++ & - & & - & \\
\hline & & Maturation zone & + &,$+ \mathrm{st}++$ & & - & \\
\hline & & Mature & + & + , st ++ & & - & \\
\hline & Hypocotyl & & + & ++ & & - & \\
\hline & Shoot meristem & & + & + & & ++ & \\
\hline & Leaf primordia & & + & - & & ++ & \\
\hline & Petioles & &,$++ \mathrm{vt}+++$ &,$+ \mathrm{vt}++$ & &,$+ \mathrm{vt}++$ & \\
\hline & Cotyledons & Blade &,$+ \mathrm{vt}++$ & + (faint) & & ++ & \\
\hline \multirow{12}{*}{$\begin{array}{l}\text { 10/11-day old } \\
\text { seedlings }\end{array}$} & Primary root & Cap & ++ & ++ & + & + & - \\
\hline & & Cell division zone & ++ & ++ & + & + & - \\
\hline & & Elongation zone & ++ & + & + & + & - \\
\hline & & Maturation zone & ++ & + & ++ & + & - \\
\hline & & Mature & ++ &,++ st +++ &,++ st +++ & ++ & st ++ \\
\hline & & Root hairs & & ++ & ++ & ++ & $++^{*}$ \\
\hline & Hypocotyl & & + & ++ &,$+ \mathrm{vt}++$ & + & $\mathrm{vt}++$ \\
\hline & Apex & Meristem & +++ & ++ & ++ & + & +++ \\
\hline & & Leaf primordia & ++ & - & + & + & $+(\mathrm{tp}+++)$ \\
\hline & Cotyledons & &,$++ \mathrm{vt}+++$ & $++(\mathrm{gc}++), \mathrm{vt}+++$ &,$+ \mathrm{vt}++$ & + & $\begin{array}{l}++(\mathrm{vt}+++ \\
\mathrm{tp}+++, \mathrm{gc}++)\end{array}$ \\
\hline & Leaf & Petiole &,$+ \mathrm{vt}++$ &,$++ \mathrm{vt}+++$ & & + & + \\
\hline & & Blade &,$+ \mathrm{vt}++$ & $-(\mathrm{vt}++, \mathrm{gc}+, \operatorname{tr}++)$ &,$+ \mathrm{vt}++$ & + & $+(\mathrm{vt}++$, hy +++$)$ \\
\hline \multirow[t]{21}{*}{ Mature plants } & Roots & Cap & +++ & + & & & \\
\hline & & Cell division zone & +++ & - & & & \\
\hline & & Elongation zone & + & & & & \\
\hline & & Maturation zone & + & st + & & & \\
\hline & & Mature & + &,+ st ++ & & & \\
\hline & Stem & Pith & + (faint) & + & & & \\
\hline & & Phloem & +++ & ++ & & & \\
\hline & & Xylem & ++ & + & & & \\
\hline & & Cortex & + & ++ & & & \\
\hline & Rosette leaves & Petioles & &,$++ \mathrm{vt}+++$ & & & \\
\hline & & Leaf blades &,$+ \mathrm{vt}+++$ &,$- v t+++$ & & & \\
\hline & Cauline leaves & Petioles & & ++ & & & \\
\hline & & Leaf blades &,$+ \mathrm{vt}++$ &,$- v t++$ & & & \\
\hline & Flowers & Pedicel & +++ & + & & & \\
\hline & & Sepals & $\mathrm{vt}+$ & + & & & \\
\hline & & Petals & - & + (faint) & & & \\
\hline & & Anthers & - & - & - & & \\
\hline & & Stamen stalk & $\mathrm{vt}++$ &,$+ \mathrm{vt}++$ & - & tp + & \\
\hline & & Style & ++ & + & - & & \\
\hline & & Stigma & - & + & + & & \\
\hline & & Silique wall & ++ & ++ & $a b+$ & $a b+$ & \\
\hline
\end{tabular}

Results are summarized for: GPA1 (Huang et al. 1994); AGB1 (this study); AGB1, AGG1 and AGG2 (Chen et al. 2006b). Highlighting indicates similarities between $A G B 1 p::$ GUS and other expression patterns, blank spaces indicate that no data was reported. Expression strength: - not present; + low; ++ medium; +++ high

$a b$ abscission zone, $g c$ guard cells, hy hydathodes, $s t$ stele, $t p$ tips, $t r$ trichomes, $v t$ vascular tissue

${ }^{\text {a }}$ below shoot/root junction only

of leaves. AGBlp::GUS expression in the blade and vascular tissue of cotyledons is also observed for both $A G G 1$ and $A G G 2$, and guard cell-specific expression for $A G G 2$
(Chen et al. 2006b). Those differences observed are likely due to the inherent limitations of promoter::GUS fusion analysis such as missing regulatory elements contained 
within introns, untranslated regions, or regions outside the promoter fragment. Additionally, some differences may arise from variations in histochemical staining techniques or plant growth conditions.

$A G B 1 p:: G U S$ expression is consistent with plant G-protein functions

In addition to shared staining patterns with previously reported G-protein subunit promoter-GUS fusion studies, the $A G B 1 p:$ :GUS expression pattern contains several features that are consistent with known or predicted functions of plant G-proteins. A recurring feature is the expression of all four subunits in vascular tissue across a variety of organs and developmental stages (Table 1; Weiss et al. 1993). This is consistent with the suggested role of GPA1 in nutrient accumulation or transport (Weiss et al. 1993; Huang et al. 1994). In yeast, sucrose is sensed via a Gprotein, and given that GPAl mutants are hypersensitive to ABA and sugar inhibition of germination (Ullah et al. 2002), this role has been proposed for plant G-proteins in relation to control of seed germination and seedling development (Rolland et al. 2006). Expression of the $A G B 1 p:: G U S$ fusion in the vascular and mesophyll tissue of seedling cotyledons in close proximity to carbohydrate reserves may reflect involvement of AGB1 in such a role.

Another recurring feature of plant G-proteins is expression in meristematic regions, previously attributed to a role in regulation of cell division (Weiss et al. 1993; Huang et al. 1994) and since confirmed for both GPA1 and AGB1 (Ullah et al. 2001, 2003). Recently, a study using knockout mutants suggested different roles for $\mathrm{G} \alpha$ and $\mathrm{G} \beta \gamma$ in the regulation of cell proliferation in roots (Chen et al. 2006a). In the root apical meristem, it was found that $\mathrm{G} \alpha$ is a positive modulator of cell division, while the $\mathrm{G} \beta \gamma$ dimer acts as a negative modulator by sequestering $\mathrm{G} \alpha$ in the heterotrimer complex. In contrast, $\mathrm{G} \beta \gamma$ was shown to be an attenuator of lateral root formation, and $\mathrm{G} \alpha$ a positive regulator, probably by sequestration of $\mathrm{G} \beta \gamma$. The expression pattern of $A G B 1 p::$ GUS in roots of 11-day-old seedling is in good agreement with these functions. In the primary root, AGB1p::GUS is strongly expressed in the root meristem and the adjacent zone of cell division (Fig. 3k), consistent with its role in regulating cell division. The strong expression of $A G B 1 \mathrm{p}:: G U S$ in the stele of the primary root may reflect a role for AGB1 in repressing initiation of lateral roots from the pericycle.

Guard cell-specific expression of AGB1p::GUS in seedling leaves and cotyledons matches the well established role for G-protein involvement in ABA regulation of water loss through stomata. GPAl transcripts are present in guard cells (Wang et al. 2001), and studies using Arabidopsis knockout mutants have shown that GPA1 mediates
ABA inhibition of inward $\mathrm{K}^{+}$channels and stomatal opening, but not stomatal closure (Wang et al. 2001; Mishra et al. 2006). The specific expression of both $A G B 1$ and $A G G 2$ in guard cells suggests that they may function in stomatal regulation together with GPA1.

Trichomes and the root cap are potential locations for AGB1 signalling functions

Trichome-specific expression of the AGB1p::GUS fusion raises the question of what signalling functions plant G-proteins may have in this specialized cell type. Although there is evidence that the unicellular leaf trichomes of Arabidopsis are involved in defence against insects, detoxification of heavy metals and other stress responses (GutierrezAlcala et al. 2000; Wienkoop et al. 2004), their functions are not fully understood. Trichomes are potentially an ideal point for plants to sense many environmental signals such as light and pathogen elicitors, and expression of AGB1 in this location could reflect a role in the perception of such stimuli. Alternatively, a trichome-localized heterotrimer could mediate wound- or pathogen-induced signals from within the plant, such as jasmonic acid, which has been linked to Gproteins (Trusov et al. 2006) and is known to influence trichome proliferation in response to mechanical wounding (Traw and Bergelson 2003). Although trichome-specific expression was not previously detected for either $A G B 1$, $A G G 1$ or $A G G 2$ promoter-GUS fusions, it was detected for five of the 15 AtMLO gene family members, which are candidate Arabidopsis GPCRs (Chen et al. 2006b).

Like trichomes, the root cap functions as an important sensory location, as it is the first point of contact for the growing root system with the soil environment. Indeed, genes involved in sensing and responding to biotic and abiotic environmental signals have been identified as one of four major categories of transcripts expressed specifically in the root cap of maize (Jiang et al. 2006). Thus specific expression of the AGB1p::GUS in the root cap could reflect the involvement of AGB1 in sensing soil signals such as pathogen elicitors or nutrients. Expression in the root tip has been identified in GUS fusions of GPA1 (Huang et al. 1994) and the G-protein regulator RGSI (Chen et al. 2006b), though in both cases expression was not specific to the root cap. It is interesting to note that root cap-specific expression similar to $A G B 1$ has been observed for the Arabidopsis AtPLA IIA gene, which encodes a phospholipase $\mathrm{A}_{2}$ isoenzyme (Rietz et al. 2004). Phospholipase $A_{2}$ is a known plant G-protein coupled effector, mediating phytoalexin responses to elicitor signals transduced by $\mathrm{G} \alpha$ through transient intracellular proton fluxes (Viehweger et al. 2006). Hence, specific expression of AGB1 in the root cap could reflect coupling to phospholipase $A_{2}$ in pathogen responses or other signalling roles. 
Localization of AGB1 at the plasma membrane and in nuclei

The proximity of the AGB1-GFP fluorescent signal to the periphery of the cytoplasm, and its dissimilarity to both non-targeted and ER-targeted GFP patterns suggest that it is localized at the plasma membrane. Association of the AGB1-GFP fusion with the plasma membrane is consistent with evidence that AGB1 is a peripheral, membrane-associated protein (Obrdlik et al. 2000), and recent localization data using a yellow fluorescent protein-AGB1 fusion (Chen et al. 2006a). Node-like structures in the plasma membrane similar to those formed by the AGB1-GFP fusion have been observed for GFP-tagged GCR1 (Humphrey and Botella 2001), and may represent caveolae, specialized plasma membrane structures that are highly enriched in signalling proteins including G-proteins and GPCRs (White and Anderson 2005). The presence of the AGB1-GFP fusion in the nucleus as well as the plasma membrane is in agreement with previous subcellular fractionation data for the tobacco $\mathrm{G} \beta$ (Peškan and Oelmüller 2000). These results concur with examples of nuclear associated G-proteins in various mammalian cell types, where they are known to be involved in mitosis and adipogenesis, and may also function in nuclear protein import and phospholipase $\mathrm{C} / \mathrm{Ca}^{+2}$ signalling (Willard and Crouch 2000). However, a role for $\mathrm{G}$ proteins in plant nuclei is yet to be discovered.

Significance of cell-specific expression and subcellular localization for plant G-protein signalling

In summary, we present evidence that $A G B 1$ is expressed in a complex manner throughout most organs and developmental stages of Arabidopsis, with significant similarities to other Arabidopsis G-protein subunits. The AGBI expression pattern observed is in agreement with the available functional data, and in addition identifies trichomes and the root cap as potential new locations for Gprotein functioning in plants. Finally, our results show that AGB1 is present at the plasma membrane, and provide further evidence that plant $\mathrm{G} \beta$ subunits are located in the nucleus, suggesting that plant G-protein signalling may be compartmentalized at the subcellular level. This work underscores the importance of cell-type expression and subcellular localization data in combination with functional studies for elucidating the mechanisms behind the multiple signalling roles of plant G-proteins.

Acknowledgments This research was supported by an Australian Research Council Discovery grant (DP0344924). The authors thank the members of the Plant Genetic Engineering Laboratory for their helpful discussions and proofreading. We are grateful to Dr. T. V. Humphrey for the pBS-GFP construct, Dr. J. S. Mylne for the pAOVintron-GUS and pSOV2 constructs, Dr. K. Siemering for the mGFP5-
ER Arabidopsis seeds, and Dr. A. Gnanasambandam for the nontargeted mGFP5. D. J. A. was supported by an Australian Postgraduate Research Award from the Australian Government.

\section{References}

Assmann SM (2005) G proteins go green: a plant $G$ protein signaling FAQ sheet. Science 310:71-73

Bechtold N, Ellis J, Pelletier G (1993) In planta Agrobacteriummediated gene transfer of adult Arabidopsis thaliana plants. C R Seances Soc Biol Fil 316:1194-1199

Casey PJ (1995) Mechanisms of protein prenylation and role in Gprotein function. Biochem Soc Trans 23:161-166

Chen JG, Gao YJ, Jones AM (2006a) Differential roles of Arabidopsis heterotrimeric G-protein subunits in modulating cell division in roots. Plant Physiol 141:887-897

Chen ZY, Hartmann HA, Wu MJ, Friedman EJ, Chen JG, Pulley M, Schulze-Lefert P, Panstruga R, Jones AM (2006b) Expression analysis of the AtMLO gene family encoding plant-specific seven-transmembrane domain proteins. Plant Mol Biol 60:583597

Ditta G, Stanfield S, Corbin D, Helinski DR (1980) Broad host range cloning system for gram negative bacteria: construction of a gene bank of Rhizobium meliloti. Proc Natl Acad Sci USA 77:7347-7351

Etheridge N, Trusov Y, Verbelen JP, Botella JR (1999) Characterization of ATDRG1, a member of a new class of GTP-binding proteins in plants. Plant Mol Biol 39:1113-1126

Gerlach WL, Bedbrook JR (1979) Cloning and characterization of ribosomal RNA genes from wheat and barley. Nucleic Acids Res 7:1869-1885

Gotta M, Ahringer J (2001) Distinct roles for G alpha and G beta gamma in regulating spindle position and orientation in Caenorhabditis elegans embryos. Nat Cell Biol 3:297-300

Gutierrez-Alcala G, Gotor C, Meyer AJ, Fricker M, Vega JM, Romero LC (2000) Glutathione biosynthesis in Arabidopsis trichome cells. Proc Natl Acad Sci USA 97:11108-11113

Hampoelz B, Knoblich JA (2004) Heterotrimeric G proteins: new tricks for an old dog. Cell 119:453-456

Haseloff J (1999) GFP variants for multispectral imaging of living cells. In: Sullivan KF, Kay SA (eds) Methods in cell biology: green fluorescent proteins. Academic, San Diego, pp 139-151

Haseloff J, Siemering KR (1998) The uses of green fluorescent protein in plants. In: Chalfie M, Kain S (eds) Green fluorescent protein: properties, applications, and protocols. Wiley-Liss, New York, pp 191-220

Haseloff J, Siemering KR, Prasher DC, Hodge S (1997) Removal of a cryptic intron and subcellular localization of green fluorescent protein are required to mark transgenic Arabidopsis plants brightly. Proc Natl Acad Sci USA 94:2122-2127

Hoekema A, Hirsch PR, Hookyaas PJJ, Schilperoort RA (1983) A binary plant vector strategy based on separation of vir- and Tregion of the Agrobacterium tumefaciens Ti plasmid. Nature 303:179-180

Huang H, Weiss CA, Ma H (1994) Regulated expression of the Arabidopsis $\mathrm{G}$ protein $\alpha$ subunit gene GPA1. Int J Plant Sci 155:3-14

Humphrey TV, Botella JR (2001) Re-evaluation of the cytokinin receptor role of the Arabidopsis gene GCR1. J Plant Physiol 158:645-653

Jiang K, Zhang SB, Lee S, Tsai G, Kim K, Huang HY, Chilcott C, Zhu T, Feldman LJ (2006) Transcription profile analyses identify genes and pathways central to root cap functions in maize. Plant Mol Biol 60:343-363 
Jones AM, Assmann SM (2004) Plants: the latest model system for Gprotein research. EMBO Rep 5:572-578

Kaydamov C, Tewes A, Adler K, Manteuffel R (2000) Molecular characterization of cDNAs encoding G protein $\alpha$ and $\beta$ subunits and study of their temporal and spatial expression patterns in Nicotiana plumbaginifolia Viv. Biochim Biophys Acta 25:1-3

Kohler RH (1998) GFP for in vivo imaging of subcellular structures in plant cells. Trends Plant Sci 3:317-320

Ma H, Yanofsky MF, Meyerowitz EM (1990) Molecular cloning and characterization of GPAl, a $\mathrm{G}$ protein $\alpha$-subunit gene from Arabidopsis thaliana. Proc Natl Acad Sci USA 87:3821-3825

Malbon CC (2005) G proteins in development. Nat Rev Mol Cell Biol 6:689-701

Mason MG, Botella JR (2000) Completing the heterotrimer: isolation and characterization of an Arabidopsis thaliana $\mathrm{G}$ protein $\gamma$ subunit cDNA. Proc Natl Acad Sci USA 97:14784-14788

Mason MG, Botella JR (2001) Isolation of a novel G-protein $\gamma$ subunit from Arabidopsis thaliana and its interaction with $\mathrm{G} \beta$. Biochim Biophys Acta 1520:147-153

Matkin OA, Chandler PA (1979) The U. C.-type soil mixes. In: Baker KF (ed) The UC system for producing healthy container-grown plants. University of California, Division of Agricultural Sciences, Agricultural Experiment Station, Extension Service, Berkeley, pp 68-85

Mishra G, Zhang WH, Deng F, Zhao J, Wang XM (2006) A bifurcating pathway directs abscisic acid effects on stomatal closure and opening in Arabidopsis. Science 312:264-266

Murashige T, Skoog F (1962) A revised medium for rapid growth and bioassays with tobacco tissue cultures. Physiol Plant 15:473-497

Mylne JS, Botella JR (1998) Binary vectors for sense and antisense expression of Arabidopsis ESTs. Plant Mol Biol Rep 16:257-262

Obrdlik P, Neuhaus G, Merkle T (2000) Plant heterotrimeric G protein beta subunit is associated with membranes via protein interactions involving coiled-coil formation. FEBS Lett 476:208-212

Offermanns S (2003) G-proteins as transducers in transmembrane signalling. Prog Biophys Mol Biol 83:101-130

Ohta S, Mita S, Hattori T, Nakamura K, Benfey PN, Ren L, Chua NH (1990) Construction and expression in tobacco of a betaglucuronidase (GUS) reporter gene containing an intron within the coding sequence: tissue-specific expression from CaMV 35S enhancer subdomains in early stages of plant development. Plant Cell Physiol 31:805-814

Perfus-Barbeoch L, Jones AM, Assmann SM (2004) Plant heterotrimeric $\mathrm{G}$ protein function: insights from Arabidopsis and rice mutants. Curr Opin Plant Biol 7:719-731

Peškan T, Oelmüller R (2000) Heterotrimeric G-protein beta-subunit is localized in the plasma membrane and nuclei of tobacco leaves. Plant Mol Biol 42:915-922

Pierce KL, Premont RT, Lefkowitz RJ (2002) Seven-transmembrane receptors. Nat Rev Mol Cell Biol 3:639-650

Rasband W (2005) Image J 1.33u. In. National Institutes of Health, USA

Rietz S, Holk A, Scherer GFE (2004) Expression of the patatinrelated phospholipase A gene AtPLA IIA in Arabidopsis thaliana is up-regulated by salicylic acid, wounding, ethylene, and iron and phosphate deficiency. Planta 219:743-753

Rolland F, Baena-Gonzalez E, Sheen J (2006) Sugar sensing and signaling in plants: conserved and novel mechanisms. Annu Rev Plant Biol 57:675-709

Siemering KR, Golbik R, Sever R, Haseloff J (1996) Mutations that suppress the thermosensitivity of green fluorescent protein. Curr Biol 6:1653-1663
Simonds WF, Woodard GE, Zhang JH (2004) Assays of nuclear localization of R7/G beta(5) complexes. In: Regulators of Gprotein signaling, Pt B, pp 210-223

Svab Z, Hajdukiewicz P, Maliga P (1995) Generation of transgenic tobacco plants by cocultivation of leaf disks with Agrobacterium pPZP binary vectors. In: Maliga P, Klessig DF, Cashmore AR, Gruissem W, Varner JE (eds) Methods in plant molecular biology: a laboratory course manual. Cold Spring Harbor Laboratory Press, Plainview, pp 55-77

Takahashi N, Kuroda H, Kuromori T, Hirayama T, Seki M, Shinozaki K, Shimada H, Matsui M (2004) Expression and interaction analysis of Arabidopsis Skp1-related genes. Plant Cell Physiol 45:83-91

Traw MB, Bergelson J (2003) Interactive effects of jasmonic acid, salicylic acid, and gibberellin on induction of trichomes in Arabidopsis. Plant Physiol 133:1367-1375

Trusov Y, Rookes JE, Chakravorty D, Armour D, Schenk PM, Botella JR (2006) Heterotrimeric G proteins facilitate Arabidopsis resistance to necrotrophic pathogens and are involved in jasmonate signaling. Plant Physiol 140:210-220

Ullah H, Chen JG, Young JC, Im KH, Sussman MR, Jones AM (2001) Modulation of cell proliferation by heterotrimeric G protein in Arabidopsis. Science 292:2066-2069

Ullah H, Chen JG, Wang SC, Jones AM (2002) Role of a heterotrimeric $\mathrm{G}$ protein in regulation of Arabidopsis seed germination. Plant Physiol 129:897-907

Ullah H, Chen JG, Temple B, Boyes DC, Alonso JM, Davis KR, Ecker JR, Jones AM (2003) The beta-subunit of the Arabidopsis $\mathrm{G}$ protein negatively regulates auxin-induced cell division and affects multiple developmental processes. Plant Cell 15:393-409

Viehweger K, Schwartze W, Schumann B, Lein W, Roos W (2006) The $\mathrm{G} \alpha$ protein controls a $\mathrm{pH}$-dependent signal path to the induction of phytoalexin biosynthesis in Eschscholzia californica. Plant Cell 18:1510-1523

Wang XQ, Ullah H, Jones AM, Assmann SM (2001) G protein regulation of ion channels and abscisic acid signaling in Arabidopsis guard cells. Science 292:2070-2072

Weiss CA, Huang H, Ma H (1993) Immunolocalization of the Gprotein $\alpha$-subunit encoded by the GPA1 gene in Arabidopsis. Plant Cell 5:1513-1528

Weiss CA, Garnaat CW, Mukai K, Hu Y, Ma H (1994) Isolation of cDNAs encoding guanine nucleotide-binding protein $\beta$-subunit homologues from maize (ZGB1) and Arabidopsis (AGB1). Proc Natl Acad Sci USA 91:9554-9558

Weiss CA, White E, Huang H, Ma H (1997) The G protein $\alpha$-subunit $(\mathrm{GP} \alpha 1)$ is associated with the ER and the plasma membrane in meristematic cells of Arabidopsis and cauliflower. FEBS Lett 407:361-367

White MA, Anderson RGW (2005) Signaling networks in living cells. Annu Rev Pharmacol Toxicol 45:587-603

Wienkoop S, Zoeller D, Ebert B, Simon-Rosin U, Fisahn J, Glinski M, Weckwerth W (2004) Cell-specific protein profiling in Arabidopsis thaliana trichomes: identification of trichomelocated proteins involved in sulfur metabolism and detoxification. Phytochemistry 65:1641-1649

Willard FS, Crouch MF (2000) Nuclear and cytoskeletal translocation and localization of heterotrimeric G-proteins. Immunol Cell Biol 78:387-394

Zhao DZ, Ni WM, Feng BM, Han TF, Petrasek MG, Ma H (2003) Members of the Arabidopsis-SKP1-like gene family exhibit a variety of expression patterns and may play diverse roles in Arabidopsis. Plant Physiol 133:203-217 